\title{
Solid phase microextraction, sand flies, oviposition pheromones, plaster of Paris and siloxanes-What is in common?
}

\author{
Thais Marchi Goulart ${ }^{\mathrm{a}}$, Christiann Davis Tosta ${ }^{\mathrm{b}}$, Vicente Estevam Machado ${ }^{\mathrm{c}}$, \\ Flávia Benini da Rocha Silva ${ }^{c}$, Camila Feitosa de Castro ${ }^{c}$, Dennys Ghenry Samillan Ortiz ${ }^{a}$, \\ Wanderson Henrique Cruz Oliveira ${ }^{c}$, Mara Cristina Pinto ${ }^{\mathrm{c}, *}$
}

a Universidade Estadual de Campinas (UNICAMP), Departamento de Zoologia Animal, Campinas, SP, Brazil

${ }^{b}$ Instituto Federal de São Paulo, Campus Matão, Matão, SP, Brazil

${ }^{\mathrm{c}}$ Universidade Estadual Paulista (UNESP), Faculdade de Ciências Farmacêuticas, Araraquara, São Paulo, Brazil

\section{A R T I C L E I N F O}

\section{Article history:}

Received 18 October 2016

Received in revised form 13 January 2017

Accepted 14 January 2017

Available online 18 January 2017

\section{Keywords:}

Sand flies

Nyssomyia neivai

Plaster of Paris

Siloxanes

Oviposition

SPME

\begin{abstract}
A B S T R A C T
Sand flies are natural hosts of various microorganisms. Due to their epidemiological importance, sand fly colonies are kept in laboratories to be studied in terms of their biology and vector/host/parasite interactions. In order to investigate the presence of oviposition pheromones in Nyssomyia neivai, experiments using Solid Phase Microextraction (SPME) were performed. However, siloxanes which is an external class of contamination, present in breeding containers made by plaster used to maintain sand flies in colonies, may be hindered the experiments.
\end{abstract}

Published by Elsevier B.V.

\section{Introduction}

Solid Phase Microextraction (SPME) is a solvent-free method for the extraction of volatile and semi volatile compounds first used for detecting traces of organic compounds in liquids analyses (Pawliszyn, 1995; Horák et al., 2009). Nowadays it has been used to find sexual pheromones in many insects orders, as Lepidoptera (Frérot et al., 1997), Coleoptera (Fujiwara-Tsujii et al., 2012), Diptera (Farine et al., 2012) and Hemiptera (May-Concha et al., 2015). However, SPME for detecting oviposition pheromones in insects has been found only in Hemiptera (Verheggen et al., 2008).

Oviposition pheromones studies in Phlebotomine sand flies (Diptera: Psychodidae) have been restrict to Lutzomyia longipalpis, vector of visceral leishmaniasis. Experiments with $L u$. longipalpis, using hexane extract, showed a positive response to eggs (Dougherty et al., 1993; Elnaiem and Ward, 1991) and latter

\footnotetext{
* Corresponding author at: Faculdade de Ciências Farmacêuticas, UNESP - Universidade Estadual Paulista, Araraquara, Departamento de Ciências Biológicas, Laboratório de Parasitologia, Rodovia Araraquara-Jaú km 01, 14801-902 Araraquara, SP, Brazil.

E-mail address: marap@fcfar.unesp.br (M.C. Pinto).
}

on, dodecanoic acid was identified as the oviposition pheromone (Dougherty and Hamilton, 1997). Nevertheless, there are over 900 sand flies species identified without any other oviposition pheromone detected.

Nyssomyia neivai, is a species strongly incriminated to be a vector of Leishmania (Viannia) braziliensis, etiological agent of American cutaneous leishmaniasis (Córdoba-Lanús et al., 2006; Casanova et al., 2009; Marcondes et al., 2009) and some previous behaviour experiments in our laboratory (data not shown) indicated a greater oviposition rate where previous eggs were placed. Some experiments were performed to detect a possible oviposition pheromone present in this sand fly species. Solid Phase Microextraction (SPME) and gas chromatography were used but high peaks of a contaminant, siloxane, made the analysis unfeasible. After some attempts we suspect that the plaster of Paris, the base of the sand flies breeding pots, which are used in routine to breed sand flies in laboratory conditions (Modi and Tesh, 1983), might have been the contamination source. Our aim is report and discuss the non-viability of using this method in such specific context. 
(a)

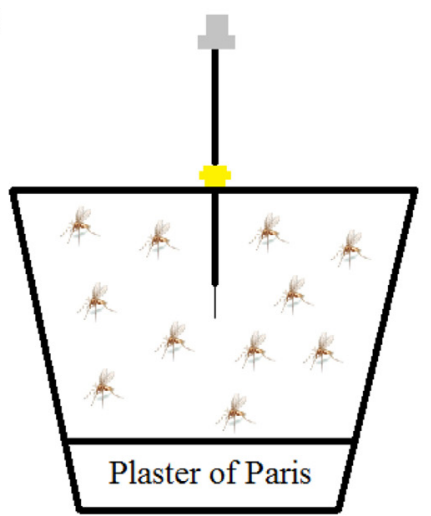

(b)

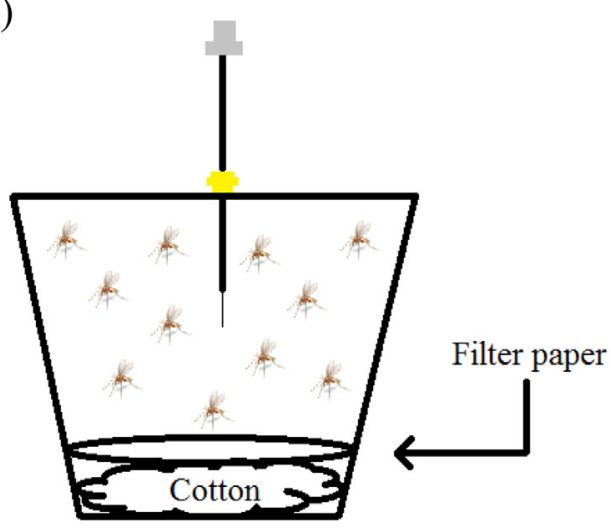

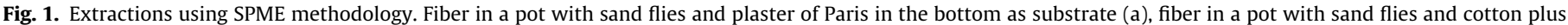
filter paper in the bottom as substrate (b).
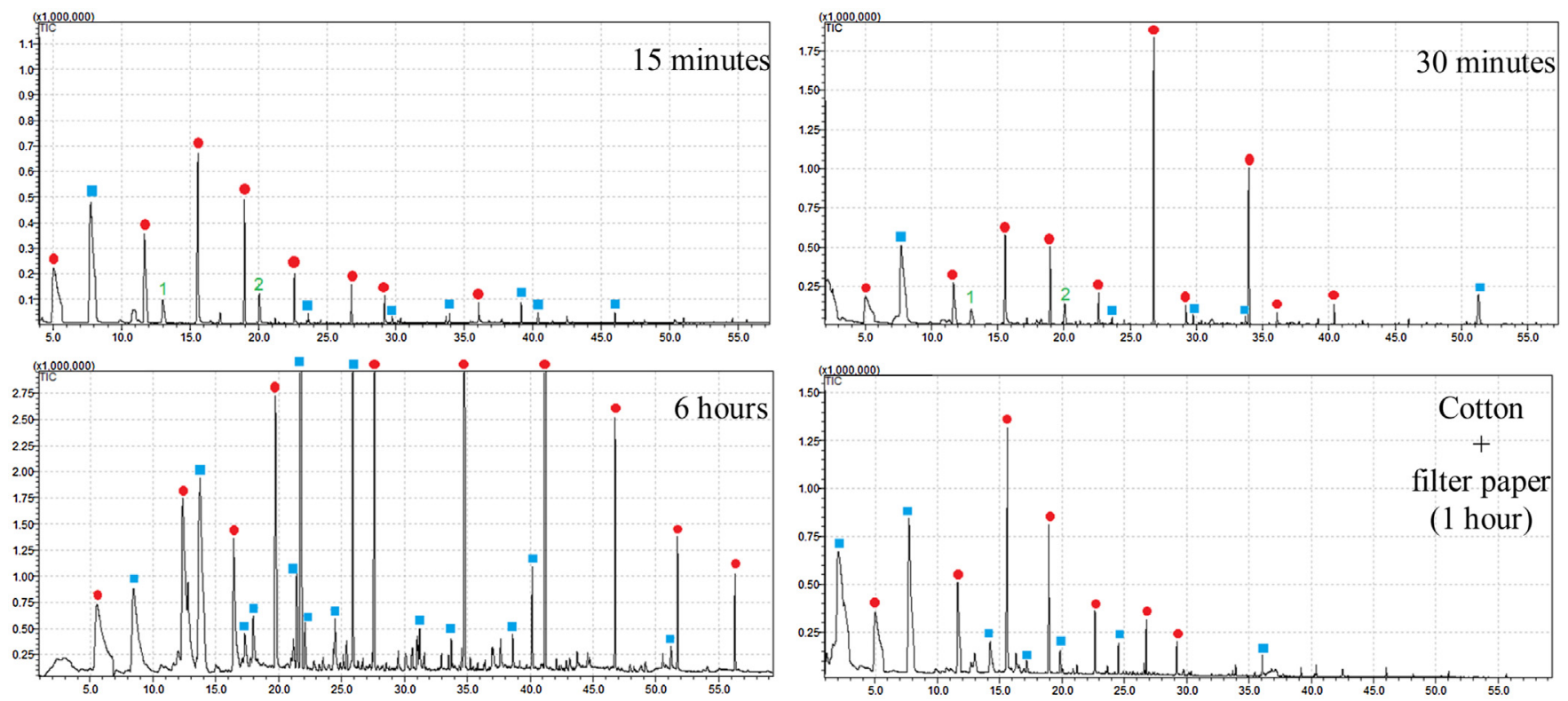

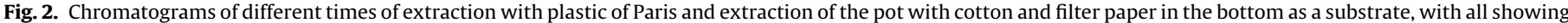

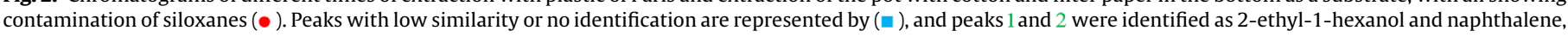
respectively.

\section{Material and methods}

Sand flies were obtained from a colony maintained at Biological Sciences Department of School of Pharmaceutical Sciences, Araraquara, São Paulo state, Brazil (Goulart et al., 2015).

All experiments were performed using SPME to extract possible oviposition volatiles.

\subsection{First trial}

The bottom of polystyrene tubes $(15 \mathrm{~mL})$ was covered with quick-drying plaster of Paris (Fortaleza ${ }^{\circledR}$ ), a round piece of its cover was removed and a mesh was glued in the empty space. Sandflies were inserted into the vials and the top was closed. A piece of cotton soaked with $30 \%$ sugar solution was placed over the mesh to allow the insects to feed. A piece of Parafilm ${ }^{\circledR}$ paper was used to seal the top and prevent the volatiles to disperse. Three treatments were performed: a) three couples of sand flies - females without blood feeding; b) three couples - females after blood feeding; c) and empty vials (as blank control). After four days, time for oviposition, silica fibers (50/30 $\mu$ m Divinylben-
zene/Carboxen/Polydimethylsiloxane - DVB/CAR/PDMS - Sigma Aldrich $^{\circledR}$ ) were inserted to extract volatiles. The exposition time to extraction was 15,30 and $45 \mathrm{~min}$ for the three treatments, in order to detect the better time. The fibers were inserted in Gas Chromatography-Mass Spectrometry (GC-MS, QP2010 Plus) for analysis on an ZB-5 column $(30 \mathrm{~m} \times 0.25 \mathrm{~mm}, 0.25 \mu \mathrm{m}$; temperature program: $50^{\circ} \mathrm{C}$ for $3 \mathrm{~min} ; 50-210^{\circ} \mathrm{C}$ at $3^{\circ} \mathrm{C} / \mathrm{min} ; 210^{\circ} \mathrm{C}$ for $3 \mathrm{~min}$ ) and the tests were carried out in triplicates (Fig. 1a).

\section{Second trial}

Considering the low number of eggs of the first experiment (49 eggs) the same procedure was repeated but at this time six couples were used and also the extraction time was increased to six hours (Fig. 1a).

\section{Third trial}

One thousand and two hundred eggs were placed inside a $2 \mathrm{~mL}$ vial. As a control, thin pieces of plaster of Paris, where the females laid the eggs, were transferred to another vial. Three fibers were 

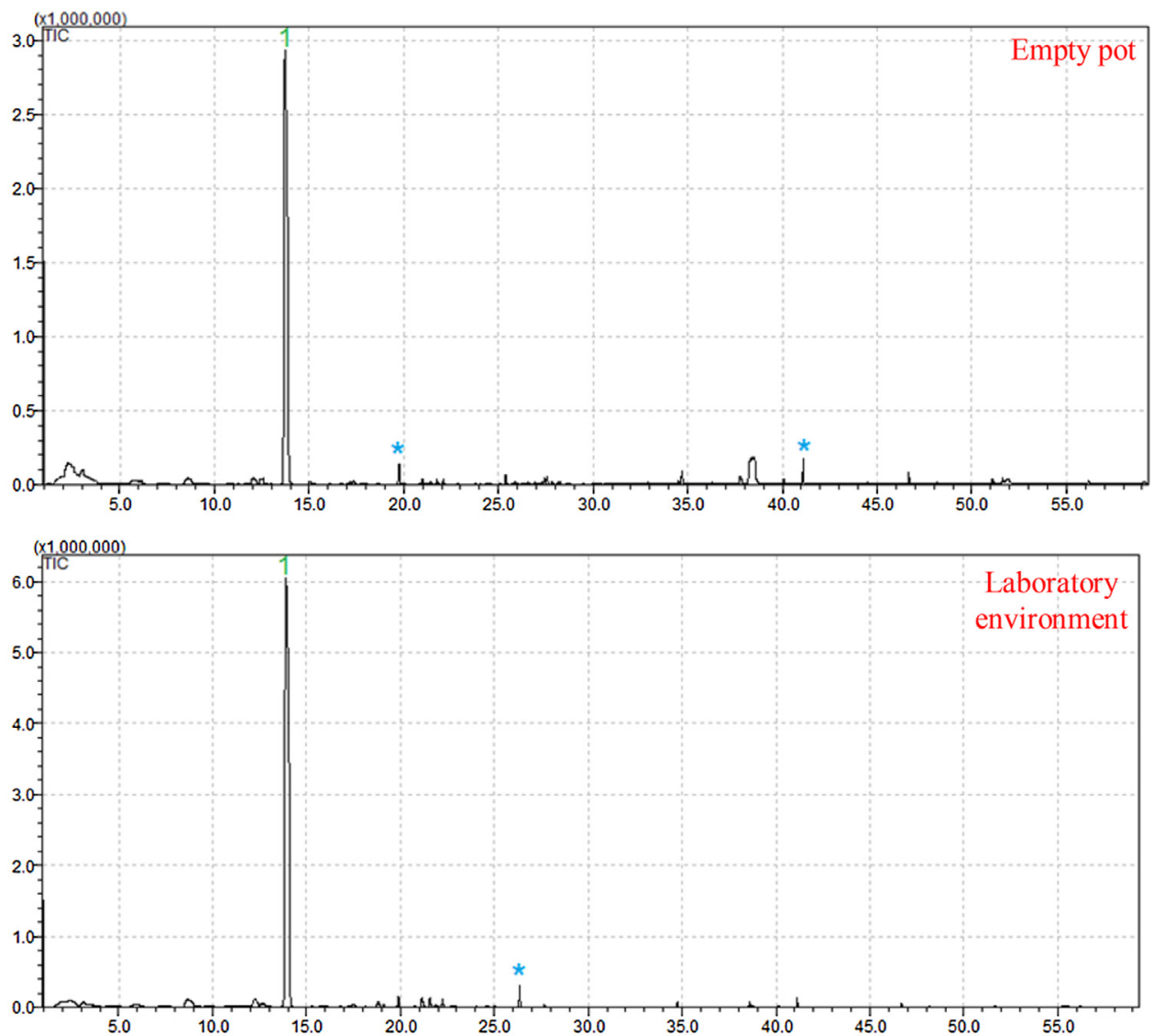

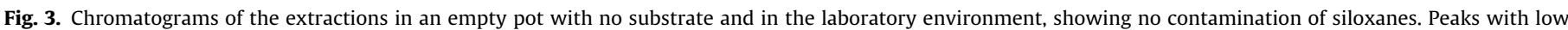
similarity or no identification are represented by $*$, and peak 1 was identified as limonene.

inserted in each vial for one hour and the analysis was carried out according to the first trial.

\section{Fourth trial}

Twenty bloodfed females were added inside a $150 \mathrm{~mL}$ polypropylene cup without plaster of Paris. Instead, it was used a moist thin layer of cotton and a sheet of filter paper in the bottom. A piece of cotton soaked with $30 \%$ sugar solution was placed over the mesh to allow the insects to feed. A piece of Parafilm ${ }^{\circledR}$ paper was used to seal the top. The same method was used on an empty cup as a control sample. Three fibers were inserted for $1 \mathrm{~h}$ and the analysis occurred as the first trial (Fig. 1b).

\section{Results}

As general results, in all experiments using plaster of Paris there was a great contamination mainly with siloxanes preventing the chromatography reading and maybe hiding possible volatiles lowest peaks. We illustrate the results with chromatograms of first and second experiments (Fig. 2). It is noticed that after 15 and $30 \mathrm{~min}$ of fibers expositions, beyond siloxanes other two peaks were also identified (2-ethyl-1-hexanol and naphthalene) whereas after $6 \mathrm{~h}$ both peaks were hidden by siloxanes and other contaminants.

In the fourth experiment, plaster of Paris was removed of breeding pots, and the peaks of siloxanes were decreased, but still present (Fig. 2).

For all trials, we analyzed blank controls only with plaster of Paris or cotton with filter paper. Contaminant compounds were present both in treatments and in blank control. We also evalu- ated one empty pot and laboratory environment (Fig. 3). In both situations siloxanes disappeared and only limonene was detected.

\section{Discussion}

Due to their epidemiological importance, sand fly colonies are kept in laboratories to be studied in terms of their biology and vector/host/parasite interactions. It is interesting to point out that despite the high number of sand flies described in Latin America, only in Lu. longipalpis oviposition pheromone has been properly identified using hexane extract (Dougherty and Hamilton, 1997). For another sand fly species, Lutzomyia renei, it has been shown a slight behaviour response of gravid females for hexane extract of eggs, but there was no progress on the identification of possible attractive compounds (Alves et al., 2003). This lack of studies and knowledge can be due to the difficulties in colonization of sand flies in laboratory or also because problems in extraction pheromone methodologies performed, which can present negative results.

Previous behavioural experiments carried out in our laboratory have suggested the presence of oviposition pheromone in $\mathrm{Ny}$. neivai. Hence, our primary aim was to identify the possible attractive compounds from the eggs of $\mathrm{Ny}$. neivai. We chose to use the SPME fibers instead of hexane extract to obtain volatiles organic compounds (VOCs) and avoid constituents compounds from the eggs. In a study performed by Farine et al. (2012) with sexual pheromones, the authors used SPME fibers to find the volatiles in the headspace of an experiment container using Drosophila melanogaster and hexane extract to identify compounds on the insect body.

A possible criticism of using SPME to extract oviposition pheromones is the low volatility of such compounds. Studies with 
alcoholic beverages have shown that SPME is a powerful method to extract volatile and semivolatile compounds of different chemical classes like alcohol, esters, carbonyl compounds and fatty acids (Demyttenaere et al., 2003; Horák et al., 2009). In both studies, dodecanoic acid, the oviposition pheromone of Lu. longipalpis, was detected using SPME fibers, although in small peaks (Demyttenaere et al., 2003).

Our first results showed a great contamination of siloxanes. However, the presence of siloxanes both in the column (ZB-5) and in the SPME fiber, initially was assumed that might these material be the sources of the contamination. Finally, it was realized that siloxanes are present in silica, a common contamination of quick-drying plaster used in the base of the sand fly breeding pots (Kellum and Smith, 1967; Grabbe et al., 1995; Oliveira, 1997). We also evaluated other three plaster trademarks (Linhal ${ }^{\circledR}$; Juntalíder ${ }^{\circledR}$ and Premium ${ }^{\circledR}$ ) using SPME and siloxanes were detected in all of them (data not shown).

In an attempt to remove the contamination source, the fourth trial was carried out without plaster of Paris. In spite of the decrease of siloxane amount, the presence of this compound could still be detected. The hypothesis is that the contamination is still remained because quick-dry plaster of Paris adhered to the legs of the colony insects as they were reared in pots with plaster. In blank controls (empty pots and environment) siloxanes did not appear showing that the problem is not the fiber, the pot, the chromatography column or the environment.

An alternative to solve this problem is to keep insects without plaster of Paris, but until now the attempts have been unsuccessfully. This fact was also reported by Rangel et al. (1985).

\section{Conclusions}

Despite being a very accurate technique and capable of detecting fatty acid, our results suggest that the use of SPME to extract volatiles compounds in environment with plaster of Paris is not feasible. Considering that for sand flies, plaster of Paris is the best base to breed them in colonies, SPME is not indicated to extract oviposition pheromones in such conditions.

\section{Competing interests}

The authors declare that they have no competing interests.

\section{Funding}

This work was supported by FAPESP (Fundação de Amparo à Pesquisa do Estado de São Paulo - Process 2012/23832-9); and Programa de Apoio ao Desenvolvimento Científico da Faculdade de Ciências Farmacêuticas at UNESP (PADC/FCFAr).

\section{Acknowledgements}

We are grateful to Dr. André Gonzaga dos Santos, Department of Natural Active Principles and Toxicology - FCF/UNESP.

\section{References}

Alves, J.C.M., Hamilton, J.G.C., Brazil, R.P., 2003. Oviposition response of Lutzomyia (Lutzomyia) renei (Martins, Falcão \&Silva) (Diptera: Psychodidae) to extracts of conspecific eggs in laboratory bioassays. Entomotropica 18, 121-126.

Córdoba-Lanús, E., De Grosso, M.L., Piñero, J.E., Valladares, B., Salomón, O.D., 2006. Natural infection of Lutzomyia neivai with Leishmania spp. in Northwestern Argentina. Acta Trop. 98, 1-5.

Casanova, C., Natal, D., Santos, F.A., 2009. Survival, population size, and gonotrophic cycle duration of Nyssomyia neivai (Diptera: Psychodidae) at an endemic area of American cutaneous leishmaniasis in southeastern Brazil. J. Med. Entomol. 46, 42-50.

Demyttenaere, J.C., Martínez, J.I., Verhé, R., Sandra, P., De Kimpe, N., 2003. Analysis of volatiles of malt whisky by solid-phase microextraction and stir bar sorptive extraction. J. Chromatogr. A 985, 221-232.

Dougherty, M., Hamilton, G., 1997. Dodecanoic acid is the oviposition pheromone of Lutzomyia longipalpis. J. Chem. Ecol. 23, 2657-2671.

Dougherty, M.J., Hamilton, J.G.C., Ward, R.D., 1993. Semiochemical mediation of oviposition by the phlebotomine sandfly Lutzomyia longipalpis. Med. Vet. Entomol. 7, 219-224.

Elnaiem, D.E., Ward, R.D., 1991. Response of the sandfly Lutzomyia longipalpis to an oviposition pheromone associated with conspecific eggs. Med. Vet. Entomol. 5 87-91.

Farine, J.P., Ferveur, J.F., Everaerts, C., 2012. Volatile Drosophila cuticular pheromones are affected by social but not sexual experience. PLoS One 7 , e40396.

Frérot, B., Malosse, C., Cain, A.-H., 1997. Solid-phase microextraction (SPME) A new tool in pheromone identification in lepidoptera. J High Resolut Chromatogr 20, 340-342.

Fujiwara-Tsujii, N., Yasui, H., Wakamura, S., Mochizuki, F., Arakaki, N., 2012. Age-dependent changes in the ratio of (R)- and (S)-2-butanol released by virgin females of Dasylepida ishigakiensis (Coleoptera: Scarabaeidae). Bull. Entomol. Res. 102, 730-736.

Goulart, T.M., de Castro, C.F., Machado, V.E., da Rocha Silva, F.B., Pinto, M.C., 2015 Techniques to improve the maintenance of a laboratory colony of Nyssomyia neivai (Diptera: Psychodidae). Parasit Vectors 8, 423

Grabbe, A., Michalske, T.A., Smith, W.L., 1995. Strained Siloxane Rings on the Surface on Silica: Their Reaction with Organosiloxanes Organosilanes, and Water. J. Phys. Chem. 99, 4648-4654.

Horák, T., Culík, J., Cejka, P., Jurková, M., Kellner, V., Dvorák, J., Hasková, D., 2009. Analysis of free fatty acids in beer: comparison of solid-phase extraction, solid-phase microextraction, and stir bar sorptive extraction. J. Agric. Food Chem. 9, 11081-11085.

Kellum, G.E., Smith, R.C., 1967. Determination of Water, Silalnol, and Strained Siloxane on Silica Surfaces. Anal Chem 39, 341-345.

Marcondes, C.B., Bittencourt, I.A., Stoco, P.H., Eger, I., Grisard, E.C., Steindel, M., 2009. Natural infection of Nyssomyia neivai (Pinto 1926) (Diptera: Psychodidae Phlebotominae) by Leishmania (Viannia) spp. in Brazil. Trans. R Soc. Trop. Med. Hyg. 103, 1093-1097.

May-Concha, I., Rojas, J.C., Cruz-López, L., Ibarra-Cerdeña, C.N., Ramsey, J.M., 2015. Volatile compound diversity and conserved alarm behaviour in Triatoma dimidiata. Parasit Vectors 8, 84.

Modi, G.B., Tesh, R.B., 1983. A simple technique for mass rearing Lutzomyia longipalpis and Phlebotomus papatasi (Diptera: Psychodidae) in the laboratory. J. Med. Entomol. 20, 568-569.

Oliveira, H.Md., 1997. Aglomerantes. In: Bauer, L.A.F. (Ed.), Materiais de Construção, vol. 1, 5 edn. LTC, Rio de Janeiro, p. 488.

Pawliszyn, J., 1995. New directions in sample preparation foranalysis of organic compounds. Trends Analyt. Chem. 14, 113-122.

Rangel, E.F., Souza d, N.A., Wermelinger, E.D., Barbosa, A.F., 1985. Estabelecimento de colonia, em laboratório, de Lutzomyia intermedia Lutz \& Neiva, 1972 (Diptera, Psychodidae, Phlebotominae). Mem. Inst. Oswaldo Cruz 80, 219-226.

Verheggen, F.J., Capella, Q., Wathelet, J.P., Haubruge, E., 2008. What makes Episyrphus balteatus (Diptera: Syrphidae) oviposit on aphid infested tomato plants? Commun Agric. Appl. Biol. Sci. 73, 371-381. 